\title{
Extensive sympatry and frequent hybridization of ecologically divergent aquatic plants on the Qinghai-Tibetan Plateau
}

\author{
Zhigang $\mathrm{Wu}^{1}$, Zhong Wang ${ }^{2}$, Dong $\mathrm{Xie}^{3}$, Juan Zhang ${ }^{2}$, Pengsen $\mathrm{Cai}^{2}$, Xing $\mathrm{Li}^{2}$, Xinwei \\ $\mathrm{Xu}^{2}$, Tao $\mathrm{Li}^{1}$, and Jindong Zhao ${ }^{1}$ \\ ${ }^{1}$ Institute of Hydrobiology Chinese Academy of Sciences \\ ${ }^{2}$ Wuhan University \\ ${ }^{3}$ Nanjing Forestry University
}

November 11, 2021

\begin{abstract}
Hybridization has fascinated biologists in recent centuries for its evolutionary importance, especially in plants. Hybrid zones are commonly located in regions across environmental gradients due to more opportunities to contact and ecological heterogeneity. For aquatic taxa, intrazonal character makes broad overlapping regions in intermediate environments between related species. However, we have limited information on the hybridization pattern of aquatic taxa across an altitudinal gradient. In this study, we aimed to test the hypotheses that niche overlap and hybridization might be extensive in related aquatic plants in alpines. We evaluated the niche overlap in three related species pairs on the Qinghai-Tibetan Plateau and assessed the spatial pattern of hybrid populations. Obvious niche overlap and common hybridization were revealed in all three pairs of related aquatic plants. The plateau edge and river basins were broad areas for the sympatry of divergent taxa, where a large proportion of hybrid populations occurred. Hybrids are also discretely distributed in diverse habitats on the plateau. Differences in the extent of niche overlap, genetic incompatibility and phylogeographic history might lead to inconsistences in hybridization patterns among the three species pairs. Our results suggested that plateau areas are a hotspot for ecologically divergent aquatic species to contact and mate and implied that hybridization may be important for the freshwater biodiversity of highlands.
\end{abstract}

\section{Hosted file}

MS-hybrids_final3_ed.docx available at https://authorea.com/users/340754/articles/468024extensive-sympatry-and-frequent-hybridization-of-ecologically-divergent-aquatic-plantson-the-qinghai-tibetan-plateau 


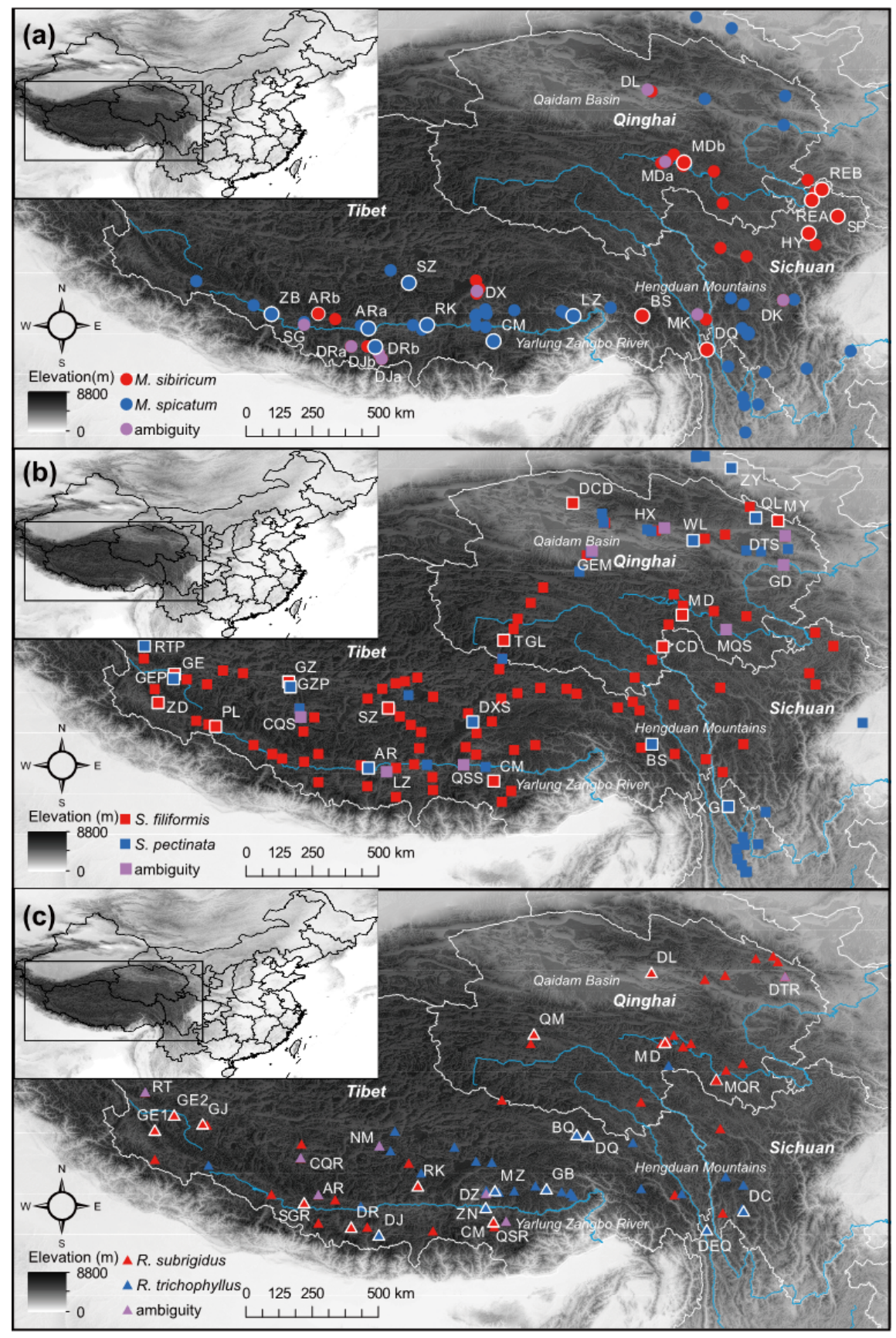

Figure 1: This is a caption 


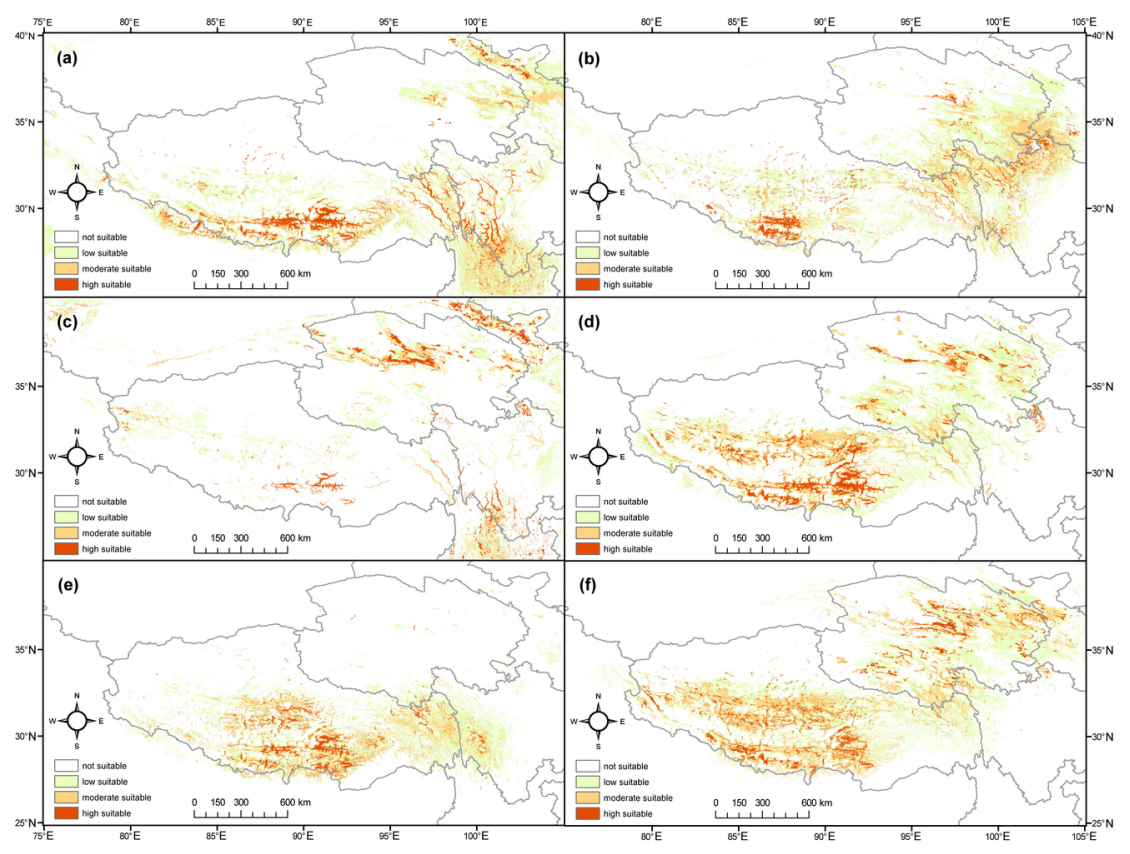

Figure 2: This is a caption 

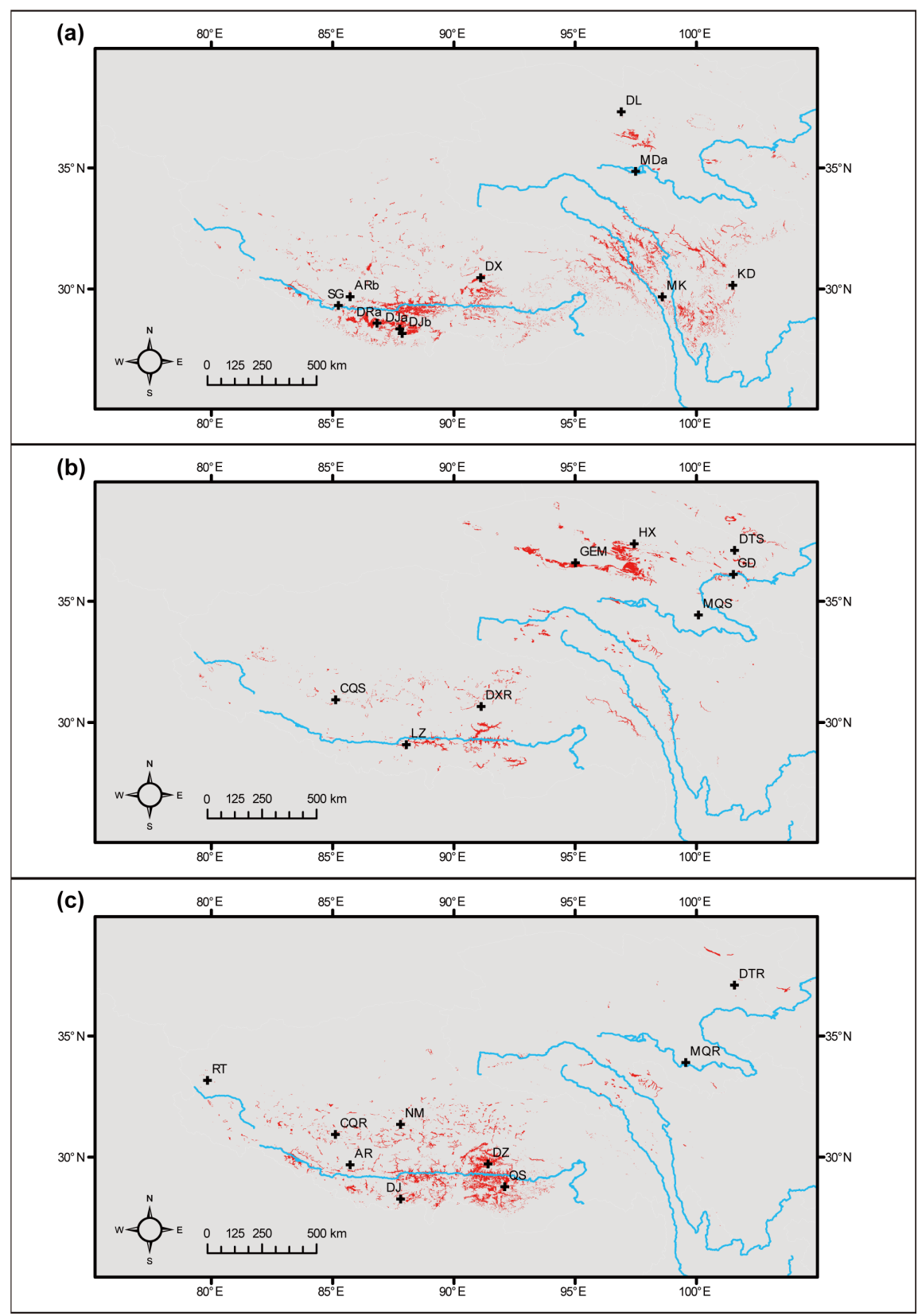

Figure 3: This is a caption 


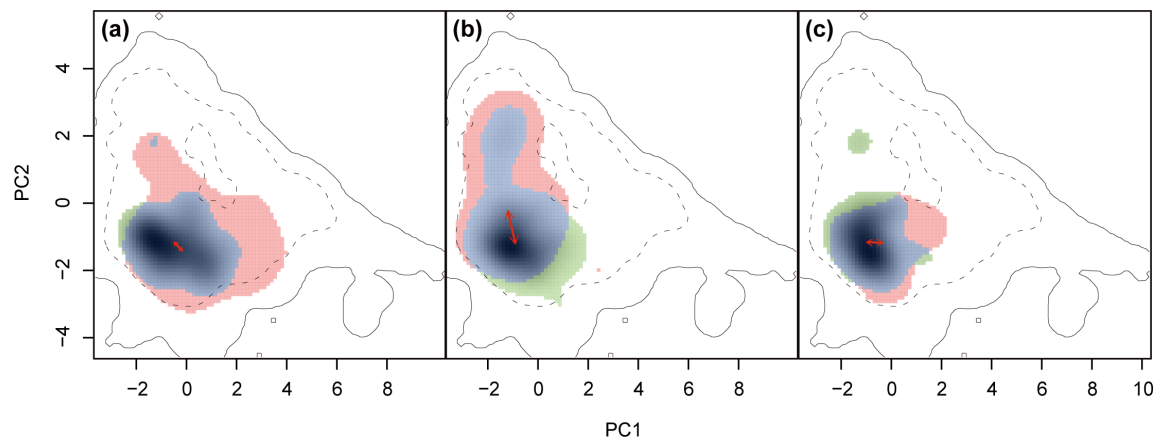

Figure 4: This is a caption

(a)

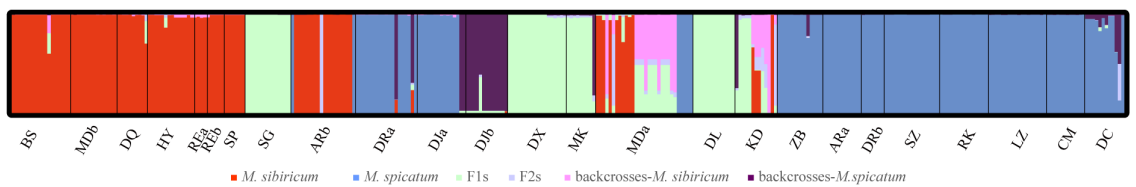

(b)

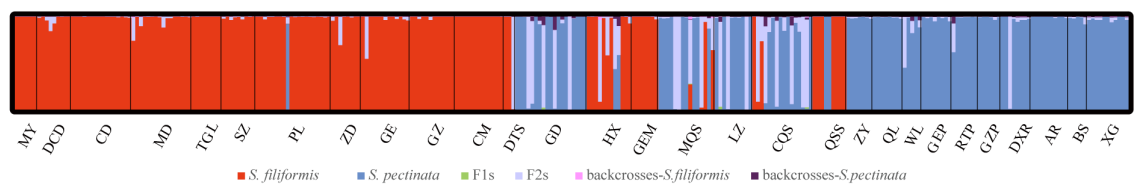

(c)

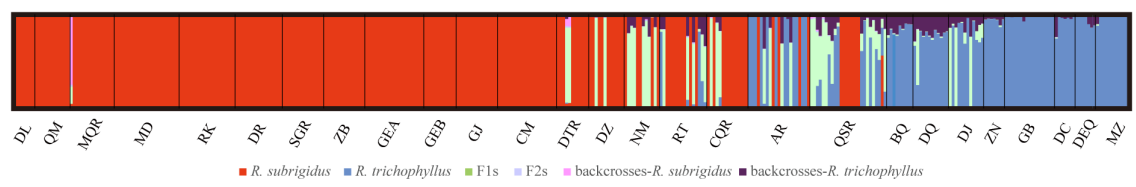

Figure 5: This is a caption

\section{Hosted file}

appendix_final3.docx available at https://authorea.com/users/340754/articles/468024extensive-sympatry-and-frequent-hybridization-of-ecologically-divergent-aquatic-plantson-the-qinghai-tibetan-plateau 